\title{
Adult attention-deficit hyperactivity disorder and child protection: review of evidence and child safeguarding guidelines
}

\author{
James Jeffs, ${ }^{1}$ Sally Cubbin, ${ }^{2}$ Kiriakos Xenitidis ${ }^{3}$
}

The Psychiatrist (2012), 36, 180-185, doi: 10.1192/pb.bp.110.033175

${ }^{1}$ Oxford Health NHS Foundation Trust, Oxford; ${ }^{2}$ St Andrew's Hospital,

Northampton; ${ }^{3}$ Maudsley Adult ADHD Clinic, London, UK

Correspondence to James Jeffs (james_jeffs@yahoo.co.uk)

First received 23 Nov 2010, final revision 22 Sep 2011, accepted 21 Nov 2011

\begin{abstract}
Summary This paper takes a broad view of the challenges to parenting faced by adults with attention-deficit hyperactivity disorder (ADHD). Issues in risk assessment are discussed. We place these in the context of the published UK national guidelines on child safeguarding for professionals working with parents who have mental disorders, and consider how this may inform practice in this field.

Declaration of interest S.C. has received payment as honorarium for consultancy work on transitional adult ADHD services from Shire. She is employed as a consultant neuropsychiatrist in acquired brain injury by St Andrew's Healthcare. K.X. has accepted payment, both personally and through his institution, including lecture fees, consultation fees and conference fees, from a number of organisations including pharmaceutical industry.
\end{abstract}

Child safeguarding has never been as starkly topical as now, following the media's indignation at the failures of various professionals to protect vulnerable children (e.g. Baby Peter and Khyra Ishaq), despite the apparent lessons from the tragic case of Victoria Climbié. This media focus on safeguarding children and the multitude of subsequent reports and guidelines are changing the perspective of adult mental health services about their responsibilities to their patients' children. It is estimated that $30 \%$ of adults with a mental illness have dependent children and that about a third of children who live with a parent who has a mental illness 'will themselves develop significant psychological problems or disorders'. ${ }^{1}$ Although in the majority of cases of child abuse there is no known history of parental mental health problems, professionals are often judged in retrospect following serious adverse outcomes. Because of this there is a growing recognition of the importance of screening for child protection issues in adult psychiatry patients, and some mental health trusts have made it mandatory to record the details of all children in close contact with all psychiatric patients.

There have been studies investigating parenting and child safeguarding for adult patients with a variety of disorders, most notably borderline personality disorder ${ }^{2}$ and intellectual disability, ${ }^{3}$ but also schizophrenia, ${ }^{4}$ bipolar affective disorder ${ }^{5}$ and depression. ${ }^{6}$ Attention-deficit hyperactivity disorder (ADHD) is a developmental psychiatric disorder typified by a constellation of symptoms starting in childhood and frequently continuing into adult life. ${ }^{7}$ We acknowledge that the concept of adult ADHD has been criticised on nosological and pharmacological grounds. ${ }^{8}$ The DSM-IV-TR criteria for ADHD include symptoms from the classic triad of inattention, impulsivity and hyperactivity. ${ }^{9}$ Symptoms that may specifically affect parenting skills include anger management difficulties, distractibility, and problems with concentration, memory and organisation. Furthermore, significant impairment of educational, relationship and occupational functioning is associated with ADHD. $^{7}$ We consider the effect of parental ADHD on children, and examine how to apply UK national guidelines on child safeguarding to adult psychiatry.

\section{Adults with ADHD and safeguarding children}

The following characteristics of ADHD provide the justification for an increased interest in child protection issues.

\section{Prevalence}

Attention-deficit hyperactivity disorder is a common disorder that begins in childhood. Childhood prevalence rates of $3-7 \%$ have been reported ${ }^{10}$ and research evidence estimates a prevalence in adulthood of $2.5-4.4 \% .^{11,12}$ The increased demands of adult life can expose ADHD-related impairments, such as occupational and social difficulties and mood lability, which were not obvious or relevant in childhood. The disorder often remains unrecognised in women as the symptoms can be less overt than in men. ${ }^{13}$ Also, females with adult ADHD may present with greater levels of emotional dysregulation, affective symptoms, sleep problems and past DSM-IV Axis I disorders than their male counterparts. $^{14}$ 


\section{Heritability}

With heritability estimates of around $76 \%,{ }^{15}$ the offspring of people with ADHD are likely to have ADHD themselves, and therefore be more challenging to parent effectively. The National Institute for Health and Clinical Excellence (NICE) guidelines state: 'Because of the increased rates of ADHD among close family members, many have children with ADHD, and need additional help to provide effective support for their children' (p. 34). ${ }^{16}$

Children with the symptoms of ADHD - even those with asymptomatic parents - are at greater risk than their peers of abuse (physical, neglectful and sexual). The severity of the reported abuse has been found to be proportionate to the number of specifically inattentive symptoms that such children exhibit. $^{17}$

\section{Treatability}

Once recognised and diagnosed, ADHD is a highly treatable condition. Treatments include pharmacotherapy and psychosocial interventions. ${ }^{16}$

\section{Comorbidity}

Antisocial personality disorder, conduct disorder, anxiety disorders and affective disorders have all been shown to be more frequent in adults with ADHD. ${ }^{18,19}$ Affective disorders with greater incidence in adults with ADHD include: major depressive disorder (67\%), dysthymia (23\%) and bipolar disorder $(17 \%){ }^{20}$ Drug misuse in parents is another factor increasing the risks to children, ${ }^{21,22}$ making the higher rates of substance use disorders found in adults with ADHD germane to child safeguarding. ${ }^{7,18,19}$

Finally, comorbidity with other neurodevelopmental disorders carries obvious additional child protection-related risks. Autism traits often coexist with hyperkinetic symptoms, and it is estimated that $0.5 \%$ of young adults would show the combination of ADHD and autismspectrum disorders. ${ }^{23}$ With regard to comorbidity of ADHD with intellectual disability, prevalence rates of $15 \%$ have been reported. ${ }^{24}$

\section{Forensic issues and domestic violence}

The high prevalence of childhood $(50 \%)^{25}$ and ongoing adult $(21.7 \%)^{26}$ ADHD in prison populations, taken together with greater recidivism and violent behaviour in offenders who have ADHD, ${ }^{27}$ might suggest a causal link between ADHD and criminality - perhaps because of high impulsivity. However, the association between childhood ADHD and later criminality is thought to be entirely dependent on the presence of comorbid childhood conduct disorder. ${ }^{28,29}$ Despite this, it remains important to carefully consider past criminal and conduct problems in adults with ADHD.

There may be a higher rate of ADHD in perpetrators of domestic violence, but there is insufficient evidence to suggest that ADHD is responsible for this - other factors may confound. $^{30}$ Parents who have been either the perpetrators or recipients of violence may struggle to meet the needs of their children, and childhood exposure to domestic violence is associated with high risks for 'developing emotional and behavioural problems, ${ }^{21}$

\section{Impact of ADHD on parenting capacity}

By its nature, ADHD makes it difficult for parents to be organised, consistent and to maintain attention when supervising their children. ${ }^{31}$ In women, ADHD is associated with having more sexual partners and experiencing a pregnancy at a younger age. ${ }^{32}$ In general, adults with ADHD are more likely to experience divorce and separation, ${ }^{18}$ as well as multiple marriages, ${ }^{7}$ and therefore their children will be exposed to greater instability in family structure. Such adults are also likely to have poorer academic qualifications, a greater likelihood of being an unskilled worker, have more unstable work records with more frequent changes in job, poorer occupational performance and a greater likelihood of impulsively leaving a job or being sacked. ${ }^{7,19}$ These social impairments are relevant because maternal youth, poverty, poor maternal education, poor marital quality, parental conflict, low paternal involvement, single parent status and low self-esteem have all been associated with neglectful parenting. ${ }^{33}$

The challenges to parenting from adult ADHD are present even before giving birth, with expectant mothers more likely to be unmarried, their pregnancy to be unplanned and their attendance at prenatal check-ups to be poorer. ${ }^{34}$ Given that 'even prior to any contact with their infant, women with ADHD symptoms have maladaptive cognitions regarding their expectations of motherhood and parenting abilities' (p. 54), ${ }^{34}$ it is hardly surprising that they develop 'lower parenting self-esteem, a more external parenting locus of control, and less effective disciplinary styles' (p. 28)..$^{35}$

Even adults without ADHD find being a parent of a child with ADHD very challenging. In general, parents of children with significant aggressive-hyperactive-impulsiveinattentive behaviours are likely to feel less satisfied, more stressed and less efficacious in their parental role than parents of children who do not have $\mathrm{ADHD},{ }^{36}$ and report a lower quality of life than the general population. ${ }^{37}$ Owing to the high heritability of the condition, parents with ADHD commonly have children with the condition, and this can be particularly challenging for families. In general, selfreported inattention in the parents of children with ADHD may be associated with lax parenting. ${ }^{38}$

There is evidence that mothers and fathers with ADHD interact with their children who also have ADHD in different ways. ${ }^{38-40}$ Mothers with ADHD tend to monitor their children with ADHD less, are less consistent in their parenting, ${ }^{39}$ and show less 'positive and involved' parenting styles. ${ }^{40}$ There is some evidence, though, that 'high levels of ADHD symptoms in mothers [ameliorate] the negative effects of child ADHD on parenting', perhaps from having more 'empathy or tolerance' towards their child. ${ }^{40}$ However, it has been suggested that this empathy and tolerance might disguise a parenting style that lacks 'consistent discipline' and 'clear boundaries'. ${ }^{40}$ Conversely, impulsive fathers may argue more with their children who have ADHD, ${ }^{38}$ and high levels of ADHD symptoms tend to have a more 'negative' effect on their parenting of children with serious ADHD. ${ }^{40}$ 
This could relate, as Psychogiou et al suggest, ${ }^{40}$ to fathers feeling 'annoyed and/or overwhelmed' by the combination of their children's ADHD and their own. Most children whose parents have ADHD are well cared for. However, a combination of the functional impairments of the disorder, as well as the commonly associated social impairments are considered by Mulsow et $a l^{41}$ to be potential risk factors for child maltreatment.

\section{How can we help protect children and support parents?}

Table 1 attempts to collate and summarise a number of important reports from UK governmental and non-governmental agencies, relevant to child welfare, which may not be widely known to adult psychiatry services. The Royal College of Psychiatrists' report Patients as Parents, ${ }^{21}$ and its successor Parents as Patients, ${ }^{22}$ highlight the responsibilities of mental health staff in safeguarding children. Although both reports emphasise that most parents with mental illness do not abuse their children, a high importance is placed on staff being aware of the needs of children, proactively considering their safety, and understanding the correct procedures to follow when concerns arise. This theme of asking adult mental health services to accept their responsibilities in this area is repeated in a number of other reports. Professionals working with adults are instructed to assess and document the parental responsibilities and key child safeguarding risk factors in relation to their patients. In addition, they are asked to share information with other agencies, acting appropriately and efficiently to ensure children are protected when safeguarding issues are suspected.

\section{Identification and treatment of adult ADHD}

Unlike many of the risk factors for neglectful parenting, ADHD symptoms are, as recognised by NICE, ${ }^{16}$ amenable to effective treatment with medication as part of a multidisciplinary holistic care package. There is some evidence that treating ADHD in adults might improve their parenting. ${ }^{56}$ In one study, methylphenidate treatment of ADHD in mothers whose children had ADHD was shown to improve consistency of discipline and reduce the use of corporal punishment on maternal self-report. ${ }^{57}$ Following randomised discontinuation of methylphenidate there was a non-significant deterioration in maternal involvement and poor monitoring/supervision in the group randomly switched to placebo. However, the sample size was small and the outcomes difficult to reliably measure, and therefore further research is needed to rigorously demonstrate the effects of treating adult ADHD on parenting capacity.

\section{Remembering comorbidity}

Comorbidity in ADHD is common and relevant to both child safeguarding and overall prognosis. It is therefore important to screen for other mental disorders in patients with ADHD. Because of their relevance to child safety, forensic and substance misuse histories should be routine and detailed. Given the wide variation in the presentation of adults with $\mathrm{ADHD}$, assessment should be made of the effect of ADHD symptoms and comorbid symptomatology on each individual patient's parenting skills.

\section{Improving service provision}

At age 18 many patients treated for ADHD throughout adolescence do not receive an ongoing local service, due to a lack of clarity in commissioning and a shortage of experienced clinicians in adult services. This occurs just at the time they are entering independent adult life, with all the demands that that places on them to gain employment and form relationships. Investment into either local specialist ADHD services or the training of general adult psychiatrists to feel competent in diagnosing and managing ADHD is required to address this unmet need. Attentiondeficit hyperactivity disorder is frequently perceived as outside the responsibility of adult psychiatry services. However, it is a very common treatable disorder, and the impairment from it can be substantial. We would suggest that knowledge and experience of ADHD should be a core skill for adult psychiatrists.

\section{Should child psychiatry/paediatric services screen parents?}

Attention-deficit hyperactivity disorder is the epitome of a psychiatric condition with high heritability. Professionals working with patients with ADHD often identify signs of the disorder in their patients' relatives. Adults commonly present for help after they have had experience of a young relative with the condition. The question remains whether child psychiatrists and paediatricians should offer screening questionnaires to parents and whether they should be able to consider direct referral to local adult services.

\section{Collaborative working}

Collaborative inter-agency working is one of the key focus areas of Crossing Bridges, ${ }^{1}$ an influential and oft-quoted manual to teach staff in adult mental health services how to address child welfare issues. Collaboration between disciplines within an organisation as well as between agencies is essential and should include Social Services, health services and family law professionals. ${ }^{58}$

Greater liaison between child and adult services when treating the same family, and more information-sharing, would be likely to protect children better. Additionally, knowledge of the impairments and treatment of one family member can be helpful to professionals working with their relatives. Adult psychiatrists have little experience in improving parenting skills in their clients and may learn much from a closer working relationship with children's services. Adult psychiatry has a responsibility to share concerns regarding child safeguarding with appropriate agencies. This is supported by the National Patient Safety Agency (NPSA), who clarified that concerns about confidentiality are not an excuse for delaying action where there are fears that a child may be at risk. ${ }^{52}$ The Royal College of Psychiatrists reminds us that 'children's rights to be safeguarded are paramount, even when they are perceived as interfering with the therapeutic relationship' (p. 8). ${ }^{22}$ 
Table 1 Summary of relevant published guidance on child safeguarding in the UK

\begin{tabular}{|c|c|}
\hline Organisation & Report \\
\hline $\begin{array}{l}\text { Department of } \\
\text { Health et } a l^{42}\end{array}$ & $\begin{array}{l}\text { Working Together to Safeguard } \\
\text { Children: A Guide to Inter-Agency } \\
\text { Working to Safeguard and Promote the } \\
\text { Welfare of Children }\end{array}$ \\
\hline
\end{tabular}

Key guidance

- 'Mental illness in a parent or carer does not necessarily have an adverse impact on a child, but it is essential always to assess its implications for any children involved in the family' (p. 9)

Welfare of Children ${ }^{\text {a }}$

- Reported that a study of 100 reviews of child deaths where abuse and neglect had been a factor showed 'clear evidence of parental mental illness in one-third of cases'

- The responsibility to 'bear in mind the welfare of children' is placed firmly with both adult and children's services

Lord Laming $^{43}$ The Victoria Climbié Inquiry ${ }^{\mathrm{a}}$

- 'I am in no doubt that effective support for children and families cannot be achieved by a single agency acting alone. It depends on a number of agencies working well together. It is a multi-disciplinary task' (p. 6)

- 'Improvements to the way information is exchanged within and between agencies are imperative if children are to be adequately safeguarded' (p. 9)

\begin{tabular}{lll}
\hline Joseph & The Right Support: Report of the Task - Criticises National Service Framework for Mental Health ${ }^{45}$ for not commenting enough on how \\
Rowntree & Force on Supporting Disabled Adults in parents with mental health issues can be enabled as parents
\end{tabular}

Rowntree Force on Supporting Disabled Adults in parents with mental health issues can be enabled as parents

Foundation $^{44} \quad$ Their Parenting Role

Carers UK ${ }^{46} \quad$ Young Carers in the UK • $29 \%$ of surveyed young carers were looking after someone with mental health needs

- Of those children caring for adults who misuse drugs or alcohol, $40 \%$ had educational difficulties and $28 \%$ had received an assessment under the Children Act 1989 (UK)

Office of the Mental Health and

Deputy Prime Social Exclusion

- Emphasises effect of mental illness on the families of those affected

Minister ${ }^{47}$

- Recommends early identification of mental health problems arounct
provision of support to parents with such mental health needs

- 'Greater awareness in adult mental health services of children's needs will help services work more supportively with parents who have mental health problems and can improve children's emotional and mental well-being' (p. 72)

Cabinet
Office $^{48}$

Reaching Out: Think Family

- Emphasises the importance of families in society generally

- Extends the social exclusion discourse

HM Putting People First: A Shared Vision

Government $^{49}$ and Commitment to the Transformation of Adult Social Care ${ }^{a}$

- Gives guidance that people 'irrespective of illness or disability, are supported to... sustain a family unit which avoids children being required to take on inappropriate caring roles' (p. 2)

Ofsted $^{50} \quad$ Learning Lessons, Taking Action: Ofsted's Evaluations of Serious Case Reviews 1 April 2007 to 31 March 2008

- Although not all children in the serious case reviews were known to Social Services, all were known to universal services such as health services

- Advocates the sharing of responsibility for child safety widely across services

Department Refocusing the Care Programme

of Health ${ }^{51} \quad$ Approach: Policy and Positive Practice Guidance $^{\text {a }}$

- 'Establishing whether a service user is a parent at the initial assessment stage is critical, and should be routine' (p. 21)

- 'Assessment, including risk assessment, should assess the potential or actual impact of menta health on parenting, the parent and child relationship, the child and the impact of parenting on the adult's mental health and what appropriate support might look like and howit can be accessed' (p. 21)

National

$\begin{array}{ll}\text { National } & \text { Rapid Response Report: Preventing Harm } \\ \text { Patient Safety } & \text { to Children from Parents with Mental }\end{array}$

Agency $^{52}$ Health Needs

- Emphasises that adult mental health services 'must always consider the child's needs'

- 'All assessment, CPA monitoring, review and discharge planning documentation and procedures should prompt staff to consider if the service user is likely to have or resume contact with their own child or other children' (p. 1)

- Concerns about confidentiality are not an acceptable excuse for delaying action 'as soon as a problem, suspicion or concern about children becomes apparent' (p. 1)

Social Care SCIE Guide 30: Think Child, Think

Institute for Parent, Think Family

Excellence $^{53}$

NICE ${ }^{16} \quad$ Attention Deficit Hyperactivity Disorder: The NICE Guideline on Diagnosis and Management of ADHD in

Children, Young People and Adults ${ }^{\mathrm{b}}$

$\mathrm{NICE}^{54} \quad$ When to Suspect Child Maltreatment ${ }^{\mathrm{b}}$

HM New Horizons: A Shared Vision

Government $^{55}$ for Mental Health ${ }^{\text {a }}$

Department Working Together to Safeguard

for Children, Children: A Guide to Inter-Agency

Schools and Working to Safeguard and Promote the

Families $^{56} \quad$ Welfare of Children ${ }^{\mathrm{a}}$
- Raises concerns about '[the] separate local criteria for adult and children's services which work against identifying the needs of the family as a whole', and call for 'family threshold criteria' - the concept that although individual members may not meet the threshold for specific services, when viewed systemically the family's needs are significant and warrant input

- Discusses parenting issues regarding children who have ADHD, but does not address the issue of parents having ADHD

- Focuses on severe maltreatment and those professionals who work directly with children

- Reiterates themes of social inclusion, interagency collaboration and information-sharing, supporting young carers, more collaborative working between adult and children's mental health services, and improved identification and management of risks

- 'Adult mental health services - including those providing general adult and community, forensic, psychotherapy, alcohol and substance misuse and learning disability services have a responsibility in safeguarding children when they become aware of, or identify, a child suffering or likely to suffer significant harm' (p. 65)

- Places a responsibility on mental health services to routinely record details of patient's responsibilities in relation to children, and to consider the support needs of patients and their children, and to do this using the CPA

Royal College Parents as Patients: Supporting the of Needs of Patients Who are Parents Psychiatrists $^{22}$ and their Children
- 'Any assessment should measure the potential or actual impact of mental health on parenting, the patient/child relationship and the child, as well as the impact of parenting on the adult's mental health' (p. 8)

- 'Referrals should be made to children's social care services under local safeguarding procedures as soon as a problem, suspicion or concern about a child becomes apparent' (p. 8)

ADHD, attention-deficit hyperactivity disorder; CPA, care programme approach; NICE, National Institute for Health and Clinical Excellence.

a. Applies predominantly to England post-devolution.

b. NICE guidance applies predominantly to England and Wales, but subject to further local review in Northern Ireland and Scotland. 
Multidisciplinary working is vital in delivering holistic care for families with ADHD where there are parenting concerns. This may involve psychiatrists, social workers, housing workers, employment professionals and others, but one professional must be identified to take the lead in coordinating the care package. Access to parenting programmes should also be made available.

\section{Risk assessment}

Parents as Patients states that 'All psychiatrists and members of multidisciplinary teams should be familiar with legal and policy frameworks in their jurisdiction in relation to safeguarding children' (p. 8). ${ }^{22}$ Establishing whether the service user 'is likely to have or resume contact with their own child or other children' (p. 8) ${ }^{22}$ is important, and professionals should be prompted to consider this in all formal documentation processes, including assessments and care programme approach reviews. This is supported by the NPSA and other organisations (Table 1), which strongly recommend that professionals record the full details of any children in close contact with adult patients, and assess the 'potential or actual impact of mental health on parenting, the parent/child relationship and the child, as well as the impact of parenting on the adult's mental health' (p. 8). ${ }^{22}$ Care programme approach and other local documentation forms should encourage professionals to do this. ${ }^{52}$

Although Parents as Patients particularly highlights parents with personality disorders, substance use disorders and intellectual disability, it also specifically mentions ADHD. The original Patients as Parents report ${ }^{21}$ discussed 'the serious risks posed to children by parents with impulsivity, high levels of aggression and unstable relationships' (p. 27). We suggest that recognition of ADHD in parents should prompt a careful risk assessment, with a particular focus on comorbid personality disorders, neurodevelopmental disorders, substance misuse and forensic problems.

\section{Concluding comments}

Most parents with ADHD are devoted to their children and able to look after them very well. For some adults, ADHD may have a positive impact on their parenting style, for example in terms of 'enthusiasm, boundless energy, and playfulness, ${ }^{31}$ The aim of our article is to make patients feel confident and competent in their parental role, through identifying their needs and signposting them to appropriate support. Even where there are parenting problems, these will often lead to relatively mild disadvantages. However, professionals working with parents who have ADHD need to remain alert to the small number of children who could be at significant risk. Further research is needed into the impact of specific symptoms on parental capacity and to investigate the efficacy of treatment strategies in improving the parenting skills of adults with ADHD.

\section{About the authors}

James Jeffs, locum consultant, Oxford Health NHS Foundation Trust; Sally Cubbin, consultant neuropsychiatrist, National Brain Injury Centre, St Andrew's Hospital, Northampton; Kiriakos Xenitidis, consultant psychiatrist and honorary senior lecturer, Maudsley Adult ADHD Clinic, London.

\section{References}

1 Mayes K, Diggins M, Falkov A. Crossing Bridges: Training Resources for Working with Mentally III Parents and Their Children. Pavilion Publishing, 1998.

2 O'Daly J. Parental borderline personality disorder and child protection. Community Pract 2003; 76: 18-20.

3 Dowdney L, Skuse S. Parenting provided by adults with mental retardation. J Child Psychology Psychiatry 1993; 34: 25-47.

4 Ramsay R, Howard L, Kumar C. Schizophrenia and safety of parenting of infants: a report from a U.K. mother and baby service. Int J Soc Psychiatry 1998; 44: 127-34.

5 Venkataraman M, Ackerson BJ. Parenting among mothers with bipolar disorder: strengths, challenges, and service needs. J Fam Soc Work 2008; 11: 389-408

6 Famularo R, Barnum R, Stone K. Court-ordered removal in severe child maltreatment: an association to parental major affective disorder. Child Abuse Negl 1986; 10: 487-92.

7 Murphy K, Barkley RA. Attention deficit hyperactivity disorder adults: comorbidities and adaptive impairments. Compr Psychiatry 1996; 37: 393-401.

8 Moncrieff J, Timimi S. Critical analysis of the concept of adult attentiondeficit hyperactivity disorder. Psychiatrist 2011; 35: 334-8.

9 American Psychiatric Association. Diagnostic and Statistical Manual of Mental Disorders (4th edn, Text Revision) (DSM-IV-TR). APA, 2000.

10 Barkley RA. Primary symptoms, diagnostic criteria, prevalence and gender differences. In Attention-Deficit Hyperactivity Disorder: A Handbook for Diagnosis and Treatment (3rd edn) (ed RA Barkley): 76122. Guilford Press, 2006.

11 Simon V, Czobor P, Bàlint S, Mészáros A, Bitter I. Prevalence and correlates of adult attention-deficit hyperactivity disorder: metaanalysis. Br J Psychiatry 2009; 194: 204-11.

12 Kessler RC, Adler L, Barkley R, Biederman J, Conners CK, Demler O, et al. The prevalence and correlates of adult ADHD in the United States: results from the National Comorbidity Survey replication. Am J Psychiatry 2006; 163: 716-23.

13 Quinn P. Treating adolescent girls and women with ADHD: genderspecific issues. J Clin Psychology 2005; 61: 579-87.

14 Robison RJ, Reimherr FW, Marchant BK, Faraone SV, Adler LA, West SA Gender differences in 2 clinical trials of adults with attention-deficit/ hyperactivity disorder: a retrospective data analysis. J Clin Psychiatry 2008; 69: 213-21.

15 Faraone SV, Perlis RH, Doyle AE, Smoller JW, Goralnick JJ, Holmgren $M A$, et al. Molecular genetics of attention-deficit/hyperactivity disorder. Biol Psychiatry 2005; 57: 1313-23.

16 National Institute for Health and Clinical Excellence. Attention Deficit Hyperactivity Disorder: The NICE Guideline on Diagnosis and Management of ADHD in Children, Young People and Adults (National Clinical Practice Guideline No. 72). British Psychological Society \& Royal College of Psychiatrists, 2008.

17 Ouyang L, Fang X, Mercy J, Perou R, Grosse SD. Attention-deficit/ hyperactivity disorder symptoms and child maltreatment: a populationbased study. J Pediatr 2008; 153: 851-6.

18 Biederman J, Faraone SV, Spencer T, Wilens T, Norman D, Lapey KA, et al. Patterns of psychiatric comorbidity, cognition, and psychosocial functioning in adults with attention deficit hyperactivity disorder. Am J Psychiatry 1993; 150: 1792-8.

19 McGough J, Smalley S, McCracken J, Yang M, Del'Homme M, Lynn D, et al. Psychiatric comorbidity in adult attention deficit hyperactivity 
disorder: findings from multiplex families. Am J Psychiatry 2005; 162: $1621-7$.

20 Millstein RB, Wilens TE, Biederman J, Spencer TJ. Presenting ADHD symptoms and subtypes in clinically referred adults with ADHD. J Atten Disord 1997; 2: 159-66.

21 Royal College of Psychiatrists. Patients as Parents: Addressing the Needs, Including the Safety, of Children Whose Parents Have Mental Illness (Council Report CR105). Royal College of Psychiatrists, 2002 (http:// www.londonscb.gov.uk/files/conference08/patients_as_parents_ cr105.pdf).

22 Royal College of Psychiatrists. Parents as Patients: Supporting the Needs of Patients Who are Parents and Their Children (College Report CR164). Royal College of Psychiatrists, 2011 (www.rcpsych.ac.uk/publications/ collegereports/cr/cr164.aspx).

23 Gillberg C, Gillberg IC, Anckarsäter H, Råstam M. Overlap between ADHD and autism spectrum disorder in adults. In ADHD in Adults: Characterization, Diagnosis, and Treatment (eds JK Buitelaar, CC Kan, PJ Asherson): 157-68. Cambridge University Press, 2011

24 Xenitidis K, Paliokosta E, Pappas V, Bramham J. ADHD in adults with intellectual disabilities. In ADHD in Adults: Characterization, Diagnosis, and Treatment (eds JK Buitelaar, CC Kan, PJ Asherson): 168-74. Cambridge University Press, 2011

25 Young S, Gudjonsson G, Wells J, Asherson P, Theobald D, Oliver B, et al. $\mathrm{ADHD}$ and critical incidents in a Scottish prison population. Pers Individ Dif 2009; 46: 265-9.

26 Retz W, Retz-Junginger P, Hengesch G, Schneider M, Thome J, Pajonk F-G, et al. Psychometric and psychopathological characterization of young male prison inmates with and without attention deficit/hyperactivity disorder. Eur Arch Psychiatry Clin Neurosci 2004; 254: 201-8.

27 Satterfield JH, Schell A. A prospective study of hyperactive boys with conduct problems and normal boys: adolescent and adult criminality. J Am Acad Child Adolesc Psychiatry 1997; 36: 1726-35.

28 Satterfield JH, Faller KJ, Crinella FM, Schell AM, Swanson JM, Homer LD A 30-year prospective follow-up study of hyperactive boys with conduct problems: adult criminality. J Am Acad Child Adolesc Psychiatry 2007; 46: 601-10.

29 Mannuzza S, Klein RG, Konig PH, Giampino TL. Hyperactive boys almost grown up. IV: Criminality and its relationship to psychiatric status. Arch Gen Psychiatry 1989; 46: 1073-9.

30 Mandell A. An investigation of the presence of adult attention deficit hyperactivity disorder behaviours in a population of court mandated domestic violence perpetrators. Dissertation Abstracts International 1999; 59: 4369A-70A.

31 Weiss M, Hechtman L, Weiss G. ADHD in parents. J Am Acad Child Adolesc Psychiatry 2000; 39: 1059-61.

32 Barkley RA. ADHD in adults. In Attention-Deficit Hyperactivity Disorder: A Handbook for Diagnosis and Treatment (3rd edn) (ed RA Barkley): 274 Guilford Press, 2006

33 Brown J, Cohan P, Johnson JG, Salzinger S. A longitudinal analysis of risk factors for child maltreatment: findings of a 17-year prospective study of officially recorded and self-reported child abuse and neglect. Child Abuse Negl 1998; 22: 1065-78.

34 Ninowski JE, Mash EJ, Benzies KM. Symptoms of attention-deficit/ hyperactivity disorder in first time expectant women: relations with parenting cognitions and behaviours. Infant Ment Health J 2007; 28: 5475

35 Banks T, Ninowski JE, Mash EJ, Semple DL. Parenting behaviour and cognitions in a community sample of mothers with and without symptoms of attention-deficit/hyperactivity disorder. J Child Fam Stud 2008; 17: 28-43.

36 Shelton TL, Barkley RA, Crosswait C, Moorehouse M, Fletcher K, Barret $S$, et al. Psychiatric and psychological morbidity as a function of adaptive disability in preschool children with aggressive and hyperactive-impulsive-inattentive behaviour. J Abnorm Child Psychol 1998; 26: 475-94.
37 Xiang Y-T, Luk ESL, Lai KYC. Quality of life in parents of children with attention-deficit-hyperactivity disorder in Hong Kong. Aust $N$ Z J Psychiatry 2009; 43: 731-8.

38 Harvey E, Danforth JS, McKee TE, Ulaszek WR, Friedman JL. Parenting of children with attention-deficit/hyperactivity disorder (ADHD): the role of parental ADHD symptomatology. J Atten Disord 2003; 7: 31-41.

39 Murray $C$, Johnson C. Parenting in mothers with and without attentiondeficit/hyperactivity disorder. J Abnorm Psychol 2006; 115: 52-61.

40 Psychogiou L, Daley D, Thompson M, Sonuga-Barke E. Testing the interactive effect of parent and child ADHD on parenting in mothers and fathers: a further test of the similarity-fit hypothesis. $\mathrm{Br} J \mathrm{Dev}$ Psychol 2007; 25: 419-33.

41 Mulsow MH, O'Neal KK, Murry VM. Adult attention deficit hyperactivity disorder, the family, and child maltreatment. Trauma Violence Abuse 2001; 2: 36-50.

42 Department of Health, Home Office, Department for Education and Employment. Working Together to Safeguard Children: A Guide to InterAgency Working to Safeguard and Promote the Welfare of Children. TSO (The Stationery Office), 1999.

43 Lord Laming. The Victoria Climbié Inquiry: Report of an Inquiry by Lord Laming. TSO (The Stationery Office), 2003.

44 Morris J. The Right Support: Report of the Task Force on Supporting Disabled Adults in their Parenting Role. Joseph Rowntree Foundation, 2003.

45 Department of Health. National Service Framework for Mental Health: Modern Standards and Service Models. Department of Health, 1999.

46 Dearden C, Becker S. Young Carers in the UK: The 2004 Report. Carers UK, 2004.

47 Office of the Deputy Prime Minister. Mental Health and Social Exclusion: Social Exclusion Unit Report. ODPM Publications, 2004.

48 Cabinet Office, Social Exclusion Task Force. Reaching Out: Think Family. Analysis and Themes from the Families At Risk Review. Cabinet Office, 2007.

49 HM Government. Putting People First: A Shared Vision and Commitment to the Transformation of Adult Social Care. HM Government, 2007.

50 Ofsted. Learning Lessons, Taking Action: Ofsted's Evaluations of Serious Case Reviews 1 April 2007 to 31 March 2008. Ofsted, 2008.

51 Department of Health. Refocusing the Care Programme Approach: Policy and Positive Practice Guidance. Department of Health, 2008.

52 National Patient Safety Agency. Rapid Response Report: Preventing Harm to Children from Parents with Mental Health Needs. NPSA, 2009.

53 Social Care Institute for Excellence. SCIE Guide 30: Think Child, Think Parent, Think Family: A Guide to Parental Mental Health and Child Welfare. SCIE, 2009 (http://www.scie.org.uk/publications/guides/guide30/ assessment.asp).

54 National Institute for Health and Clinical Excellence. When to Suspect Child Maltreatment (NICE Clinical Guideline 89). NICE, 2009.

55 HM Government. New Horizons: A Shared Vision for Mental Health Department of Health, 2009.

56 Evans SW, Vallano G, Pelham W. Treatment of parenting behavior with a psychostimulant: a case study of an adult with attention-deficit hyperactivity disorder. J Child Adolesc Psychopharmacol 1994; 4: 63-9.

57 Chronis-Tuscano A, Seymour KE, Stein MA, Jones HA, Jiles CD, Rooney $M E$, et al. Efficacy of osmotic-release oral system (OROS) methylphenidate for mothers with attention-deficit/hyperactivity disorder (ADHD): preliminary report of effects on ADHD symptoms and parenting. J Clin Psychiatry 2008; 69: 1938-47.

58 Xenitidis K, Jeffs J, Cubbin S. Therapeutic support for parents with mental disorders - focus on neurodevelopmental disorders (learning disbilities, autism, ADHD). In Mental Health and Family Law: The Collected Papers of the 2009 Interdisciplinary Conference, Dartington Hall (eds Rt Hon Lord Justice Thorpe, M Faggionato): 117-21. Family Law, 2010. 